\title{
Implantable RF telemetry for cardiac monitoring in the murine heart: a tutorial review
}

\author{
Robert Sobot
}

\begin{abstract}
Research and development of implantable RF telemetry systems intended specifically to enable and support cardiac monitoring of genetically engineered small animal subjects, rats and mice in particular, has already gained significant momentum. This article presents the state of the art review of experimental cardiac monitoring telemetry systems, with strong accent on the systems designed to work with a dual pressure-volume conductance-based catheter sensor. These commercially available devices are already small enough to fit inside a left-ventricle of a mouse heart. However, if the complete system is to be fully implanted and the subject allowed to freely move inside a cage, the mouse's small body size sets harsh constrains on the size and power consumption of the required electronics. Consequently, significant portion of the research efforts is directed towards the development of low-volume and -power electronics, as well as RF energy harvesting systems that are required to serve as the energy source to the implanted telemetry instead of the relatively very bulky batteries.
\end{abstract}

\section{Introduction}

Congestive heart failure (CHF), a condition in which the heart fails to pump efficiently, is identified as one of the major cardiovascular diseases; e.g. in 2008 cardiovascular diseases accounted for $29 \%$ of all deaths in Canada [1]. In order to evaluate a heart's functionality, cardiovascular researchers rely mostly on the shape and position of the heart's pressure-volume (PV) loops [2], with genetically engineered small animal subjects, such as mice, rats, and rabbits being the most important models used for researching diseases. Similarly to piston in a car engine, a heart is described by PV loops, where a heart of a healthy person is capable of closing a PV loop with large surface, i.e. it is capable of generating a large stroke volume (SV); versus a failing heart that is capable of generating much smaller SV (Figure 1). Therefore, it is essential to collect simultaneous data related to both blood pressure $(P)$ and volume $(V)$ of a heart on a beat-to-beat basis. To that end, one of the first micromachined (MEMS) type of $P$ sensors suitable for blood pressure monitoring was reported in [3], and soon after Baan et al. [4,5] followed by

Correspondence: rsobot@uwo.ca

Western University, Electrical and Computer Engineering, London, Ontario, N6A 5B9, Canada reporting the development of a catheter with the embedded conductance-based $V$ sensor. Today, these two types of sensors are commercially available as a single-package dual-sensor device that is small enough to be implanted into a mouse heart [6,7]. However, the small size of a mouse body still presents great challenge if the supporting electronics and antenna are to be encompassed as well.

Consequently, today's biomedical researchers still rely on small, heavily distorted samples of PV data collected by the external data-collection unit during an open heart operation while the subject is fully anesthetized. Thus, the lack of micro-sized implantable telemetry systems for cardiac monitoring remains an important problem. Therefore, it is extremely important to develop a fully implantable cardiac telemetry microsystem that can safely fit into small mouse's body and, eventually, be permanently implanted into a human heart [8]. Then, the researchers will be able to continuously monitor the subject's heart condition by collecting real-time data over longer periods of time while, in the case of the small animal subjects, the subject is fully conscious and freely moving inside a cage specifically designed for that purpose, i.e. inside a cage with the embedded communication antennas and RF energy harvesting infrastructure.

\section{是 Springer}

(c) 2013 Sobot; licensee Springer. This is an Open Access article distributed under the terms of the Creative Commons Attribution License (http://creativecommons.org/licenses/by/2.0), which permits unrestricted use, distribution, and reproduction in any medium, provided the original work is properly cited. 


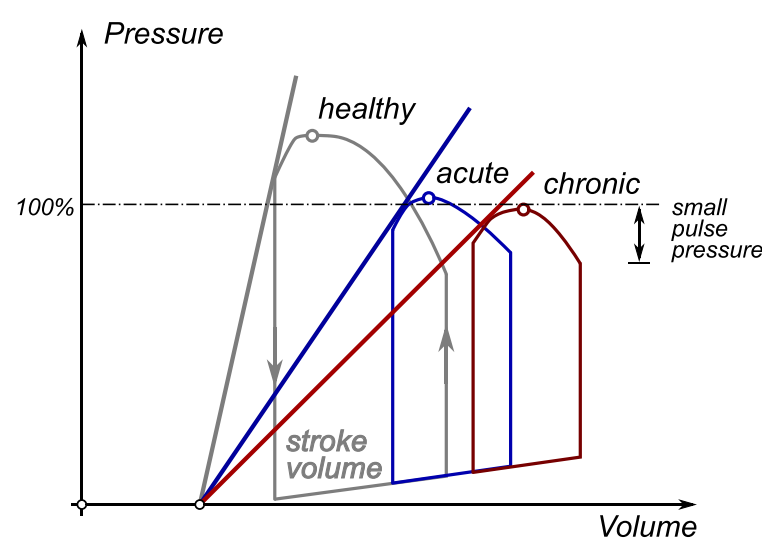

Figure 1 Left ventricular (LV) PV loops in a healthy person (grey PV area) and for persons with acute (blue PV area) or chronic, congestive (red PV area) cardiac failure.

\section{Review}

RF telemetry has already become an indispensable tool in clinical applications. A "radio pill" first reported in [9], over the time, has evolved into a fully functional "video pill" [10] that is now almost routinely used to monitor $\mathrm{pH}$, temperature, and the human digestive system from the inside. The contemporary research on cardiac RF telemetry systems for a murine heart monitoring, however, may be broadly grouped under the following four themes:

\section{Conductance catheter model}

Accurate modelling of the relationship between the blood conductance and the beating heart's volume is a very complex problem, which forces the researchers to rely on onerous use of numerical tools to develop practical working models [11]. Today, Baan's linear equation [12] and Wei's nonlinear equation [13] form the core of the conductance volumetric catheter model that is currently accepted by the researchers.

However, first apparent limitation of the conductance catheter based methodology is due to the random finite resistance of a heart's muscle, which causes dynamic fluctuations and the current leakage through the heart walls [14-16]. Second drawback of this volumetric method is its relativity, thus the need for the calibration methodology $[15,17]$.

At the same time, the alternative noninvasive reported methods for the volumetric measurements are mostly based on ultrasound scanning [18], and three-dimensional (3D) microcomputed tomography (CT) imaging techniques [19]. However, these methods require a full size scanning equipment located in the laboratory, and numerically intensive post-processing of the data. In this article, we focus specifically on conductance catheter based invasive cardiac monitoring methods, while the detailed review of the noninvasive methods is beyond the scope of this article and will be addressed in another publication.

\section{Wireless energy transfer}

Although the reported energy harvesting techniques exploit various physical principles [20], due to the power consumption level and system size constrains specific to the mouse cardiac implant application, choice of the applicable power sources is drastically limited. Hence, the inductive resonance-based coupling techniques are emerging as the leading method [21], with various optimization proposals recently reported in [22-24]. In this article we focus specifically on inductive resonance-based coupling technique for RF energy harvesting.

\section{RF telemetry}

A typical RF telemetry system consists of four main modules: (a) the sensor interface; (b) RF transceiver; (c) control; and (d) energy source and the voltage regulator (Figure 2). For instance, recently reported state-of-the-art experimental RF telemetry system [24] supports a single pressure sensor for a real-time blood pressure monitoring in a mouse. There, both the capacitive MEMS sensor and the accompanying RF transmitter are implanted in abdomen of a large mouse, i.e. outside of the heart. Similarly, while using their own capacitive MEMS pressure sensor, Chow et al. [25] reported different cardiac pressure monitoring system that has been approved for clinical use. Being work in progress, contemporary research is focused on further optimization of the RF telemetry subcircuits for their power consumption and size within other biomedical and robotic applications [26,27]. In this article we review typical telemetry designs and the future trend.

\section{Biocompatible package}

Design of a biocompatible package and antenna intended for RF telemetry systems is, by all measures, very involved phase of the overall design process. Occasionally, design details of implantable micro-telemetry package itself are

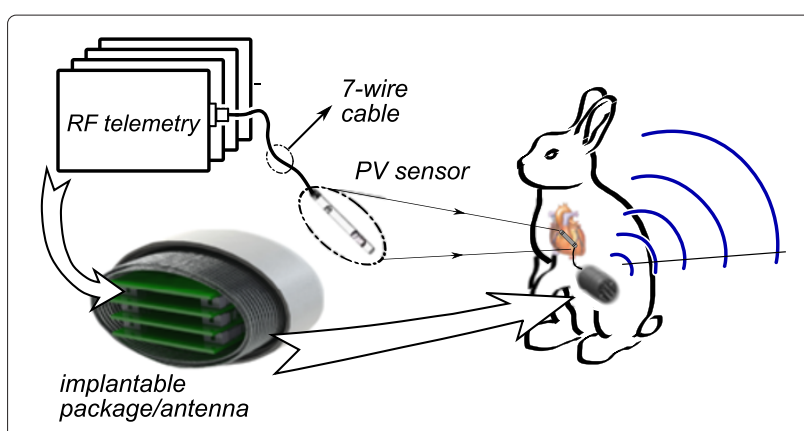

Figure 2 RF telemetry system based on conductance catheter PV sensor for murine heart monitoring. 
reported within the context of the overall system [24-26], while most of the published studies related to design of a package intended for various implantable systems focus only on the specific technological steps [28]. It is interesting, however, to observe that most current implantable designs, for instance a commercially available Cochlear implant, RF telemetry system in [24], and an active RFID micro tag [29], follow the same traditional system-level design approach. That is, the system package and the antenna are usually designed and manufactured as the two separate entities. Recently, the researchers are reporting more creative approach to the antenna/package assembly design, as is partially reported in [25], which resulted in the novel use of a well established medical stent device as structural support of the implant as well as an antenna for simultaneous wireless telemetry and powering. Thus, the electro-mechanical design process of a biocompatible package and the accompanying antenna for RF power and data transfer is still as much an art as it is engineering.

\section{Conductance based catheter}

Basic heart volumetric method proposed by Baan et al. $[4,5,12]$ is based on obtaining $S V$ and cardiac output by the means of an intra-cardiac measurement of the electrical impedance of the time-varying conductance of blood contained within the left LV cavity. Custom designed conductance based catheter with several pairs of ring electrodes, whose geometry is the known variable, is inserted directly into the subject's LV cavity (Figure 3). Assuming constant AC current flow through the outmost pair of the ring electrodes (here, the rings $a$ and $d$ ), and constant value of the blood conductance, the heart volume is then estimated by measuring conductance between the two inner electrodes (i.e. the rings $b$ and $c$ ). Due to the size of a mouse heart, the catheter size is drastically limited and it allows only for two pairs of the ring electrodes, where the two inner electrodes (i.e. $b$ and $c$ ) define one cylindrical segment (whose height is $L$ ) of the heart volume. That is, a larger heart volume would allow for multiple pairs of ring electrodes and, therefore, it would be electrically divided into several smaller volume segments stacked on top of each other. In the case of larger animal subjects, it is not only possible to use a catheter with more than one inner pair of electrodes, but also it is possible to implant two catheters-one in each ventricle [30]. If the two-catheter measurement is to be used in a mouse heart then, in order to be able to fit inside of the RV, a new significantly smaller PV catheter must be developed first (Figure 3).

\section{Baan's linear model}

As a material, blood has both conductive and dielectric properties, hence, each inner segment of the heart volume is considered as the equivalent resistor in parallel with a capacitor, whose height is determined by the

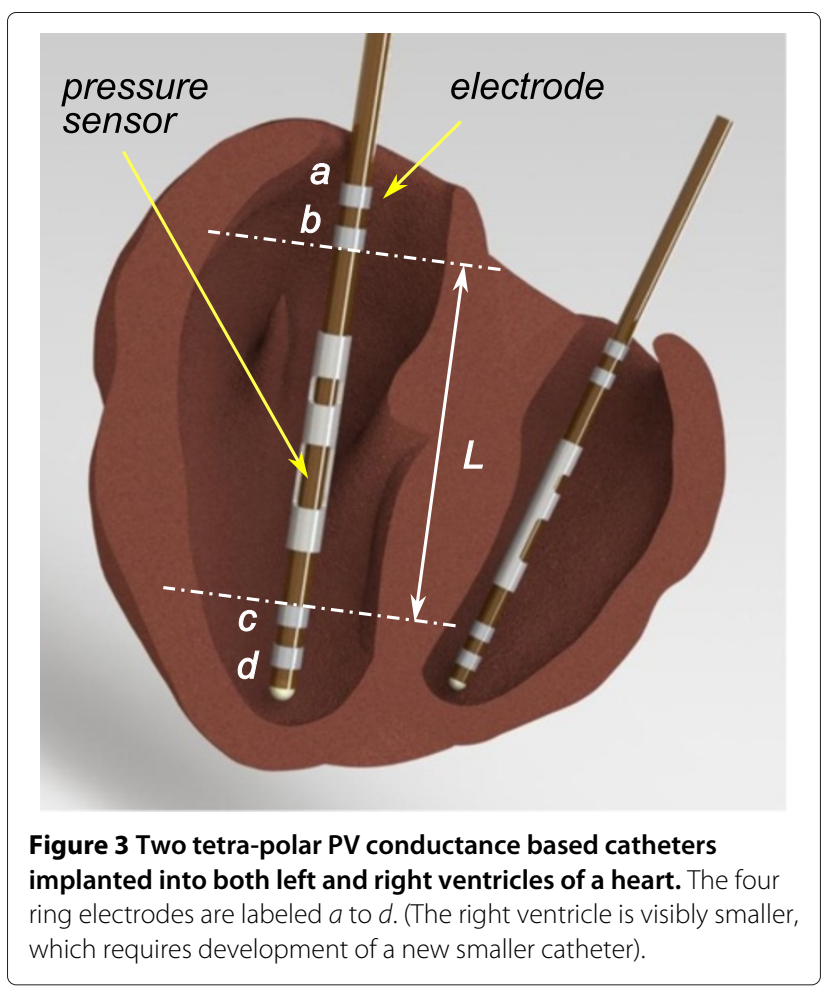

inter-electrode pair distance $L$ and time-varying median cross-sectional area $A(t)$ (Figure 3 ).

In deriving his linear model Baan et al. [12] makes the following four crude assumptions: (a) the intracardiac electric field distribution is uniform; (b) the ventricular wall is perfectly insulated from the cavity blood, i.e. the total measured conductivity is strictly due to the blood and not to the heart's muscle; (c) a heart cavity has a cylindrical shape; and (d) the catheter is stationary and always perfectly centred along the cylinder's axis.

Hence, straightforward calculation shows that the timevarying admittance (i.e. current/voltage ratio) of a segment between two adjacent electrodes, consists of an in-phase component:

$$
g(t)^{\prime}=\frac{1}{R(t)}=\frac{\sigma}{L} A(t)+\frac{\epsilon}{L} \frac{d A(t)}{d t}
$$

and an out-of-phase component

$$
g(t)^{\prime \prime}=\omega \frac{\epsilon}{L} A(t)
$$

where, $R(t)$ is blood resistance, $\sigma \approx 0.7 \Omega^{-1} m^{-1}$ is conductivity and $\epsilon \approx 7 \times 10^{-10} \mathrm{Fm}^{-1}$ ) dielectric constant of blood [31]. Therefore, the second term in (1) may be neglected, because the change of cross-sectional area $A(t)$ in time is tied to the heart pulse (a mouse heart beets up to $700 \mathrm{bpm}$ ), hence in the first approximation the 
second term is consider not large enough to relative to the first term. Linear approximation of the measured segment volume $\Delta V$ is simply volume of the cylindrical shape:

$$
\Delta V(t) \approx A(t) \times L
$$

after substituting (3) into (1), we write:

$$
g(t)^{\prime}=\frac{1}{R(t)}=\frac{\sigma}{L^{2}} V(t) .
$$

Therefore, volume of the segment is calculated by measuring conductance that corresponds to the resistance across the catheter length $L$, which is expressed as the difference of conductances between the first two electrodes $(a b)$ and electrodes $(a c)$, i.e.

$$
\Delta V(t) \approx \frac{L^{2}}{\sigma}\left(\frac{1}{R_{a b}}-\frac{1}{R_{a c}}\right)=\frac{L^{2}}{\sigma} g_{b}(t)=\rho L^{2} g_{b}(t)
$$

where, $g_{b}(t)$ is the instantaneous blood conductance, and $\rho=1 \sigma$ is the blood resistivity in $(\Omega m)$. By visual inspection of Figure 3 it should be obvious that this linear approximation is very crude for the case of a heart that is small relative to the catheter's size, as is the case of a small mouse. However, if the heart is large and if the catheter is manufactured with several inner electrode ring pairs, then the total instantaneous volume $V(t)$ is measured more accurately as the sum of the individual volume sections $\Delta V_{n}(t)$, as

$$
V(t)=\sum_{n=1}^{n \rightarrow \infty} \Delta V_{n}(t)
$$

where, each volume section $\Delta V_{n}(t)$ is calculated as in (5). Additionally, this method produces relative measurement that is function of the blood conductance $\sigma$, therefore the absolute value of the conductance must be determined beforehand by using an independent measurement methods.

Simplest way to increase accuracy of (5) is to add experimentally determined linear correction factors

$$
V(t)=k \rho L^{2} g_{b}(t)+V_{c}
$$

where, $k$ is an empirical slope correction factor, and $V_{c}$ is the linear offset empirical correction factor. The two empirical linear correction factors are determined by comparing values for the volume $V(t)$ as calculated from the analytical expression (7) with the experimentally determined value after using an electromagnetic flow probe or Doppler ultrasound volume measurement method. Nevertheless, we conclude that the first order linear approximation model is overly simplified.

\section{Wei's nonlinear model}

In order to compensate for the intrinsic error caused by the nonuniform internal electric field, while still keeping the other assumptions used in the linear model, Wei et al. [13] suggested the following nonlinear model.

Blood conductance $g_{b}$ can be found by definition

$$
g_{b}=\frac{I}{V}=\frac{\oint_{a} \vec{J} d \vec{a}}{-\int_{l} \vec{E} d \vec{l}}=\frac{\oint_{a} \sigma \vec{E} d \vec{a}}{-\int_{l} \vec{E} d \vec{l}},
$$

where $I$ is current (A), $V$ is voltage (V), $\vec{E}$ is electric field intensity $(V m), \vec{J}$ is current density $\left(A m^{2}\right), a$ is a surface enclosing the source electrode, $l$ is the path length for potential calculation, and $\sigma$ is the blood conductivity (the reciprocal of blood resistivity $\rho$ ).

Straightforward application of Laplace's equations $\nabla^{2} V=0$ and $\vec{E}=-\nabla V$ for the case of cylindrical coordinate system $(r, \theta, \varphi)$ yields

$$
\begin{aligned}
\frac{1}{r^{2}} \frac{\partial}{\partial r}\left(r^{2} \frac{\partial V}{\partial r}\right) & +\frac{1}{r^{2} \sin \theta} \frac{\partial}{\partial \theta}\left(\sin \theta \frac{\partial V}{\partial \theta}\right) \\
& +\frac{1}{r^{2} \sin ^{2} \theta}\left(\frac{\partial^{2} V}{\partial \varphi^{2}}\right)=0
\end{aligned}
$$

The additional assumption that must be made is that the source electrodes are spheres with radius placed in an infinite homogeneous medium, which makes potential $V$ independent of $\varphi$. It can be shown $[13,14]$ that the total blood admittance $Y$ is

$$
\begin{aligned}
Y= & \frac{\pi d\left(d^{2}-L^{2}\right)\left(\sigma_{b}+j \omega \varepsilon_{b}\right)}{4 L} \\
& \times\left(\frac{1}{\sqrt{a_{0}^{2}+d^{2} / 4}}-\frac{1}{\sqrt{R^{2}+d^{2} / 4}}\right)
\end{aligned}
$$

where, $\sigma_{b}$ and $\varepsilon_{b}$ are the electrical conductivity and permittivity, respectively, of the fluid, $\omega$ is frequency of the AC current, $d$ is distance between two source ring electrodes $(a$ and $d), L$ is the distance between the two receiving inner ring electrodes $(b$ and $c)$, and $a_{0}$ is radii of the spherical electrodes; and that the nonlinear analytical function for volume $V$ vs. blood conductance $g_{b}$ looks as

$$
V=\frac{\beta}{\left(g_{\text {inf }}-g_{b}\right)^{2}}-\frac{\beta}{g_{\text {inf }}^{2}}
$$

where,

$$
\beta=f\left(S V, g_{\text {inf }}, g_{\text {bmax }}, g_{\text {bmin }}\right)
$$

is the empirical calibration factor and, $S V$ is the real SV as measured by using an independent method, $g_{\text {inf }}$ is conductance of an infinite thick medium (i.e. assuming that the radius of the sensing electrodes is small enough so that their influences on the electric field distribution are negligible), $g_{b \max }$ is the maximum blood conductance, and $g_{b m i n}$ is the minimum blood conductance. The blood conductance changes during the stroke cycle, with minimum 
$g_{b m i n}$ at the maximum contraction point (i.e. when blood is squeezed from the heart) and maximum $g_{b \max }$ at the maximum expansion point (i.e. when heart is filled in with the blood). The nonlinearity of the model is clearly demonstrated in Figure 4, and we note that $\beta=f(S V)$, as well as being function of all the other parameters through its dependance upon $g_{\text {inf }}$, which is to say that $\beta$ is also experimentally determined correction factor.

Consequently, the performance of the analytic approximation (11) is not fully satisfying either, since the analytic approximation was derived under the assumption that the electrodes are placed in a large medium. Further experimental empirical corrections should be applied again [13].

\section{Dubois model}

The issue of parasitic conductance of the heart muscle, which from electrical perspective is parallel to the blood conductance, is addressed in $[14,32,33]$. Due to this parasitic conductance, the traditional conductance based volume measurement method fails to accurately correct for the parallel conductance contributed by the myocardium, resulting in overestimation of blood volumes.

While still relying on the cylindrical geometry of the ventricle, however with the addition of infinitely thick surrounding layer of the heart muscle, Figure 5, Dubois model builds upon the existing knowledge by specifically addressing the issue of the parallel admittance. Instead of accounting only for the blood properties, as in (10), Dubois also applies the same expression to the surrounding heart muscle tissue. Hence, the total measured admittance $(Y)$ becomes the sum of blood $\left(Y_{b}\right)$ and muscle $\left(Y_{m}\right)$ admittances, i.e.

$$
Y=Y_{b}+Y_{m}
$$

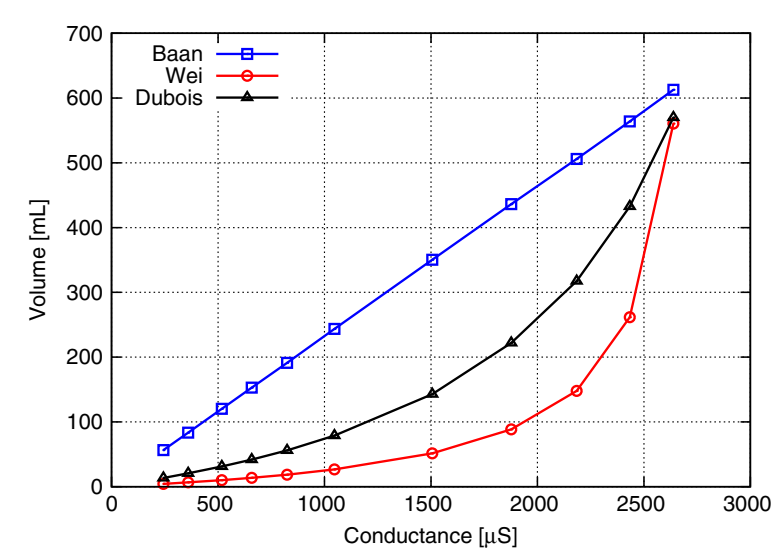

Figure 4 The conductance-volume plot of MATLAB simulation of the three models, Baan's linear, Wei's nonlinear, and Dubois model.

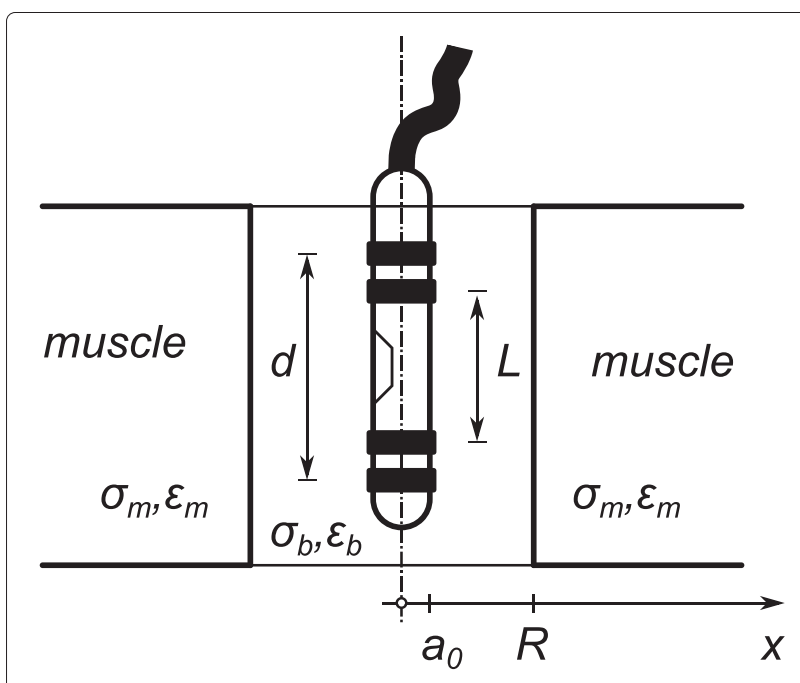

Figure 5 Geometry of catheter placed in a cylindrical ventricle with a conducting fluid surrounded with infinitely thick muscle that is used in Dubois model.

where, expressions for both blood admittance $Y_{b}$ is as per (10) with the appropriate indexes and the boundary conditions of $\left(a_{0} \leq x \leq R\right)$. The muscle admittance follows the same equation (10), however, the boundary conditions must be set as $\left(a_{0} \leq R \leq \infty\right)$ (Figure 5$)$. It can be shown [14] that analytical expression for blood volume can be expressed as

$$
V=-\pi L\left[\frac{d^{2}}{4}-\frac{\beta \pi^{2} d^{2}\left(d^{2}-L^{2}\right)(\Delta \sigma+j \omega \Delta \varepsilon)^{2}}{16 L^{2}\left(Y-Y_{\mathrm{inf}}\right)^{2}}\right]
$$

where,

$$
Y_{\mathrm{inf}}=\frac{\pi d\left(d^{2}-L^{2}\right)\left(\sigma_{b}+j \omega \varepsilon_{b}\right)}{4 L \sqrt{a_{0}^{2}+d^{2} / 4}}
$$

and, $\Delta \sigma=\left(\sigma_{m}-\sigma_{b}\right), \Delta \varepsilon=\left(\varepsilon_{m}-\varepsilon_{b}\right)$, and $\beta=f(S V, Y)$ is an empirical calibration factor that is meant to compensate for the error due to the use of cylindrical model. Muscle admittance $\left(Y_{m}\right)$ with boundary condition at $R=$ $\infty$ is $Y_{\text {inf. }}$

\section{The calibration issue}

Development of the analytical models for volumetric catheter is based on fundamental electromagnetic field theory applied to a simple cylindrical geometry. However, as it has been shown above, the set of crude simplifications has to be introduced in order to manage the mathematical complexity of the analytical model. Consequently, all analytical models developed so far rely on an independent evaluation of the SV, which is needed to experimentally 


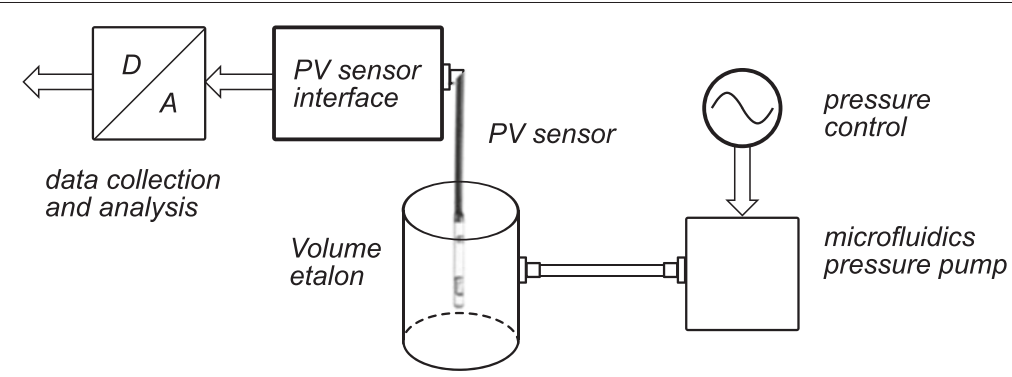

Figure 6 Conceptual block diagram of a calibration setup based on the cylindrical model.

determine value of the correction factor $\beta$. This correction factor is determined by using calibration setup based on known cylindrical etalons (Figure 6). Recently, in an attempt to reach more accurate models the researchers are introducing various numerical methodologies [15,34], which include detailed 3D models of a complete heart, Figure 7 [11]. Hence, this particular issue is one of the main topics of the current research.

\section{Wireless energy transfer}

Commonly, mobile devices depend on a battery as the energy source. However, a battery's energy density does

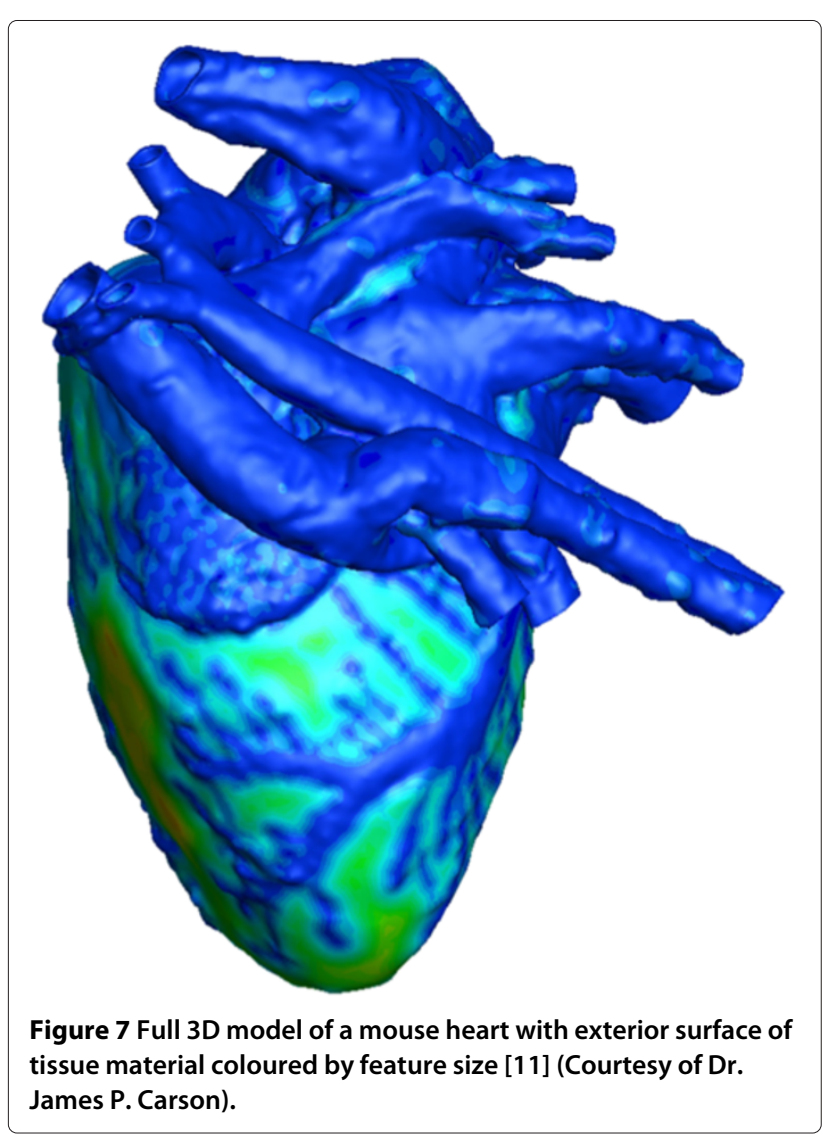

not scale at the same rate as an IC's physical size. Consequently, the battery size has become major bottleneck on the path to further miniaturization of mobile systems, which is especially important parameter for the implantable telemetry.

Overcoming this issue requires adaptation of alternative energy sources. For instance, recently, new developments and fabrication technologies have resulted in micro fuel cells [35] that are becoming competitive with the state of the art batteries. However, a holy grail of bioelectronics is to engineer biologically implantable systems that can be embedded without disturbing their local environments while harvesting from their surroundings all of the power they require. In particular, most important question is whether the implantable electronics can be powered by drawing the required energy from their surrounding tissues [36].

Various solutions to the problem of providing power to biologically implanted devices have been proposed, prototyped, or implemented [37]. Two principal solutions are currently in widespread use: single-use batteries, such as those used in implantable pulse generators for cardiac pacing, defibrillation, and deep brain stimulation, which are designed to have finite lifetimes and to be replaced surgically at intervals of several years; and inductive power transfer [38], typically accomplished transcutaneously at radio frequencies, as in cochlear implants. Inductive schemes can be used either to supply power continuously or to recharge an implanted power source [36]. A brief overview of some other physical principles that can be exploited for energy harvesting is shown in Table 1 [20]. Not all of the possible physical principles for energy harvesting are suitable for powering up microsized implantable electronics for cardiac monitoring in a mouse, which have very harsh size requirement.

Therefore, in this article we focus on the inductive power transfer techniques (Figure 8). A typical system topology includes inductive coupled RF power transfer system, RF data link, implanted AC/DC regulator, micro controller $\mu C, \mathrm{RF}$ transmitter, sensor interface, and the sensor itself (Figure 9). 
Table 1 Energy-harvesting sources

\begin{tabular}{|c|c|c|}
\hline Energy source & Performance & Note \\
\hline Ambient RF & $<1 \mu \mathrm{W} / \mathrm{cm}^{2}$ & A few mW with a short distance inductive coupled systems [21] \\
\hline \multirow[t]{2}{*}{ Ambient light } & $100 \mathrm{~mW} / \mathrm{cm}^{2}$ (direct sunlight) & Assuming common polycrystalline solar cells at $16-17 \%$ \\
\hline & $100 \mu \mathrm{W} / \mathrm{cm}^{2}$ (office light) & $\begin{array}{l}\text { efficiency, while standard monocrystalline cells approach } 20 \% \text { at } \Delta T=5^{\circ} \mathrm{C} \text {; } \\
\text { typical thermoelectric generators } \leq 1 \% \text { efficient for } \Delta T<40^{\circ} \mathrm{C}\end{array}$ \\
\hline Thermoelectric & $60 \mu \mathrm{W} / \mathrm{cm}^{2}$ & at $\Delta T=5^{\circ} \mathrm{C} ;$ typical thermoelectric generators $\leq 1 \%$ efficient for $\Delta T<40^{\circ} \mathrm{C}$. \\
\hline \multirow[t]{2}{*}{ Vibrational } & $4 \mu \mathrm{W} / \mathrm{cm}^{3}$ (human) & Predictions for $1 \mathrm{~cm}^{3}$ generators \\
\hline & $800 \mu \mathrm{W} / \mathrm{cm}^{3}$ (machine) & \\
\hline Ambient airflow & $1 \mathrm{~mW} / \mathrm{cm}^{2}$ & Demonstrated in microelectromechanical turbine at 30 liters/min \\
\hline Push buttons & $50 \mu \mathrm{J} / \mathrm{N}$ & MIT Media Lab Device \\
\hline Hand generator & $30 \mathrm{~W} / \mathrm{kg}$ & Nissho Engineering's Tug Power \\
\hline Heel strike & $10-800 \mu \mathrm{W}$ & $7 \mathrm{~W}$ potentially available ( $1 \mathrm{~cm}$ deflection at $70 \mathrm{~kg}$ per $1 \mathrm{~Hz}$ walk) \\
\hline
\end{tabular}

The basic idea of wireless energy transfer based on Tesla's coils, that is currently being exploited in many forms and modifications, is now a century old [39]. In the first approximation, the power density at the receiving $R F$ antenna is produced through $E / Z_{0}$ relation, where $Z_{0}=377 \Omega$ is the radiation resistance of free space, and $E$ is the local electric field strength. An electric field of $E=1 \mathrm{Vm}$ thus yields about $0.26 \mu \mathrm{W} / \mathrm{cm}^{2}$. This crude analysis illustrates that the freely available RF energy is very limited, unless the radiation levels are set to dangerously high level, or the receiving antenna is very close to the transmitter. Which further imposes the upper limit of the total power that can be safely transmitted through a living tissue. Currently, as a "rule of a thumb", most

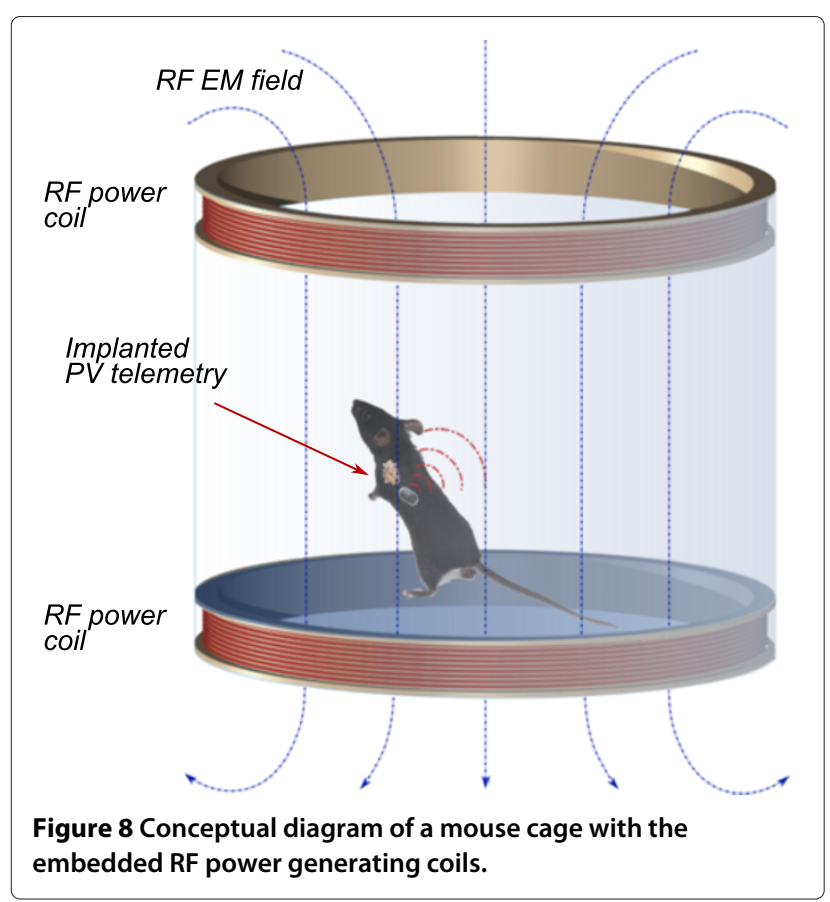

researchers arbitrary set the upper total power budget for the implantable telemetry to a few hundred $\mu \mathrm{W}$, i.e. less than approximately $300-500 \mu \mathrm{W}$.

Thus, being able to control intensity and direction of the electro-magnetic filed vector is very important, because if energy being transmitted through a living tissue has too high radiation density level, then it can permanently damage the cells it passes through. In other words, the design of a mouse cage with the embedded RF energy harvesting system, Figure 8 , is not much different from a microwave oven design.

The reason for ambiguity related to the accepted power levels is that, despite a large body of publicly available literature related to the topic of mobile phone radiation and health, there is no consensus on what energy level exactly is considered to be dangerous for the living tissue. Discussion on that topic is beyond the scope of this article, hence, in our research we take conservative approach and keep the transmitted energy levels significantly below those generated by modern cellphones.

\section{Inductive-coupling resonance}

Considering that the RF energy transmission efficiency is the main design parameter, the bottleneck of the remote powering link is generally at the inductive link because the coupling factor between the coils of the inductive link is usually very small. Therefore, these coils should be designed properly to achieve high power transfer efficiency [21,22].

Inductive-coupling-based power transfer requires two coils (primary and secondary coils), and the efficiency of power transfer between the coils is a strong function of the coil dimensions and distance between them. Therefore, the recent alternative method of resonance-based power delivery $[21,40]$ is explained through the coupled-mode theory [41], which is less sensitive to changes of the coil distance and typically employs two pairs of coils: one in 


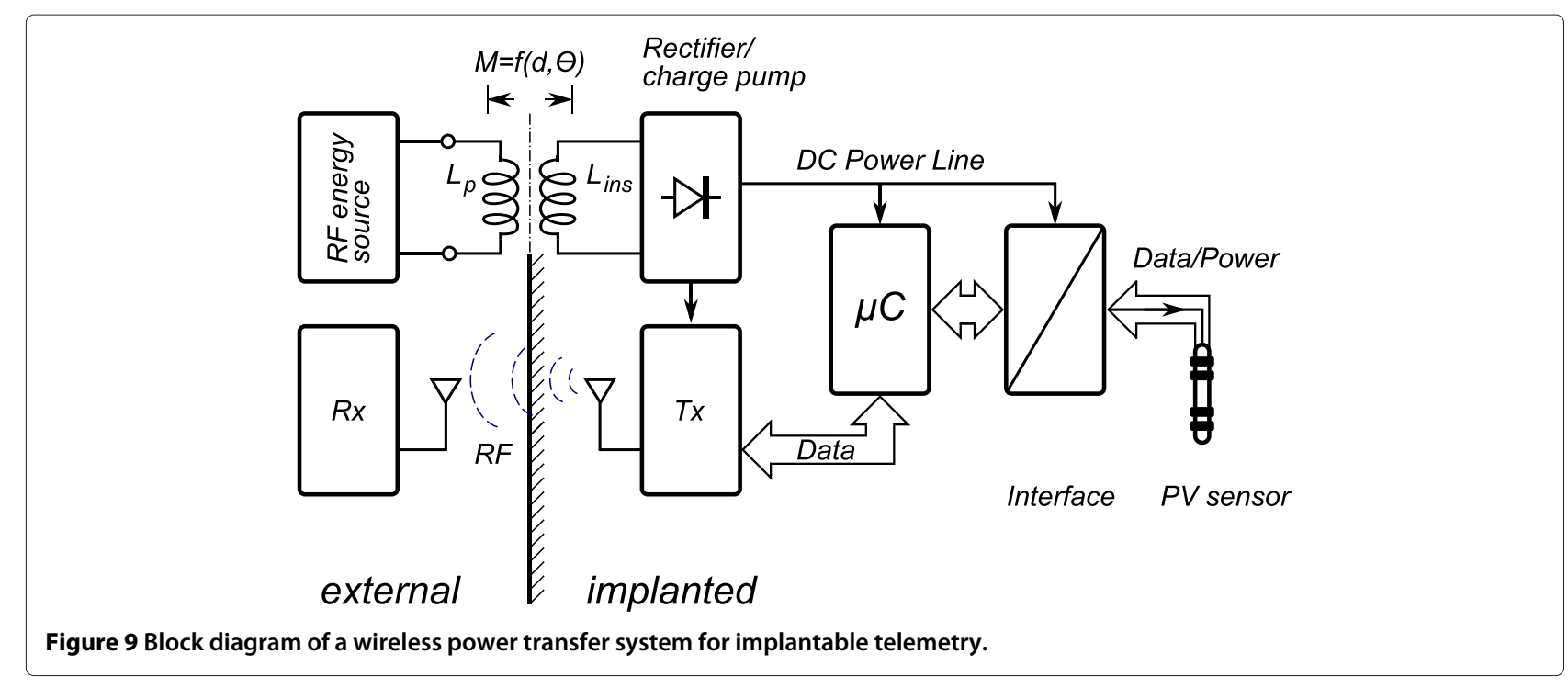

the external circuit called driver and primary coils, and the other in the implant itself called secondary and load coils (Figure 10). Most of the work in this area revolves around static large radii coils for relatively high power transfer applications [40].

However, for low-power applications when the subject carrying the implant moves freely inside the controlled space, the two inductors continuously change their relative position in space. Hence, the inductive coupling coefficient is function of both linear and angular displacements between the two coils, i.e. $M=f(d, \Theta)$, whose geometry is depicted in Figure 11. Therefore, the received energy levels vary over a wide range. This situation poses a problem for normal operation of the implanted signal processing and communication electronics. Consequently, it is important to design an efficient implantable voltage regulator that also consumes a minimal amount of energy for its own operation while providing continuous power to the load.

\section{Inductance coupling background}

Since the maximum power transfer can only be achieved when the external and implanted inductors are perfectly aligned, the challenge is to design a powering system that would have low sensitivity to the coil orientation and distance $[21,42]$. Such designs, which are mainly focused on the generation of constant minimum power level inside the subject's cage, have been investigated in [43].

When $L_{1}$ and $L_{2}$ are the self-inductance of the two coils, $M$ and $k$ are related by

$$
M=k \sqrt{L_{1} L_{2}}
$$

For two non-coaxial and non-parallel filamentary coils, the mutual inductance defined in [44] is

$$
M=\frac{\mu_{0}}{\pi} \sqrt{R_{P} R_{S}} \int_{0}^{\pi} \frac{\left(\cos \theta-\frac{d}{R_{S}} \cos \phi\right) \Psi(k)}{\sqrt{V^{3}}} d \phi .
$$

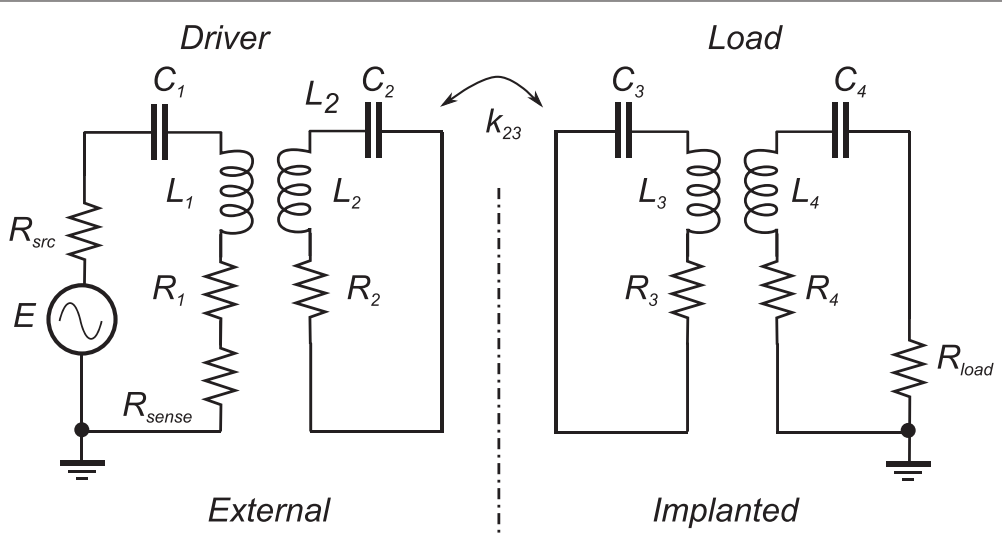

Figure 10 Electrical model of the resonance-based four-coil power transfer system. 


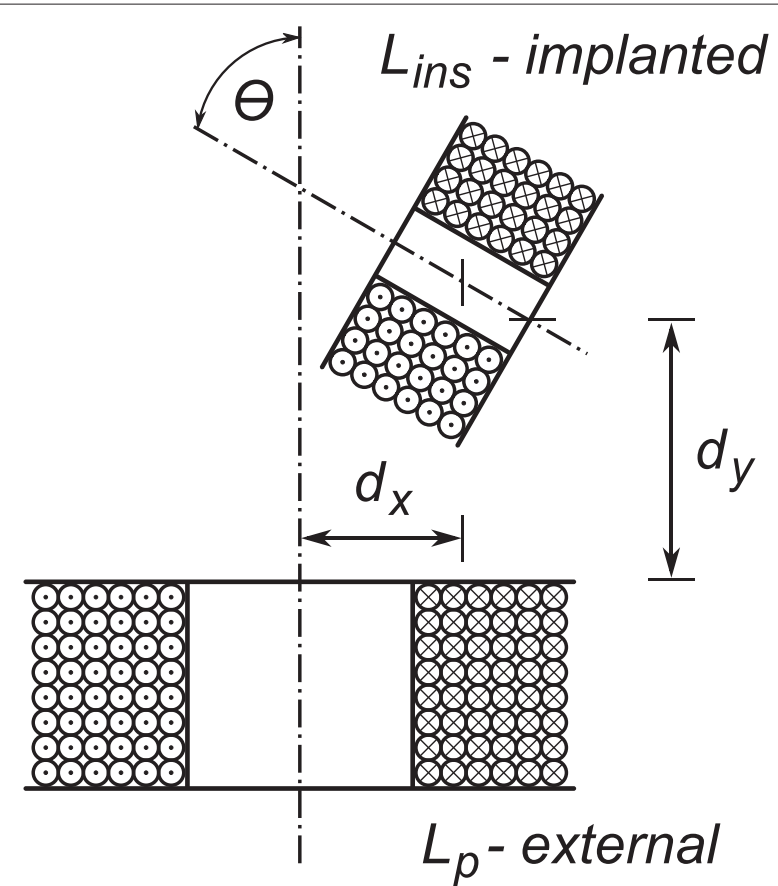

Figure 11 Diagram of two non-coaxial and non-parallel circular coils cross-section. Relative location, and therefore the coupling coefficient $M$, of the two power transfer coils (external and implanted) is defined by horizontal $\left(d_{x}\right)$, vertical $\left(d_{y}\right)$, and angular $(\theta)$ misalignments. (The plot is not to scale).

For our case of multilayer helical coils with axial and angular misalignment, we apply the filament method [45] to (17) and calculate the mutual inductance, which produces the following equation:

$$
M=\frac{N_{1} N_{2} \sum_{g=-K}^{g=K} \sum_{h=-N}^{h=N} \sum_{l=-n}^{l=n} \sum_{p=-m}^{p=m} M(g, h, l, p)}{(2 S+1)(2 N+1)(2 m+1)(2 n+1)}
$$

where

$$
\begin{aligned}
M(g, h, l, p)= & \frac{\mu_{0}}{\pi} \sqrt{R_{P}(h) R_{S}(l)} \\
& \times \int_{0}^{\pi} \frac{\left[\cos \theta-\frac{y(p)}{R_{S}(l)} \cos \phi\right] \Psi(k)}{\sqrt{V^{3}}} d \phi
\end{aligned}
$$

while denotation of all variables in (17) to (19) follows [46].

Based on numerical analysis, the resonant based power transfer methods are expected to achieve maximum power at power efficiency of approximately $85 \%$, while the maximum power efficiency is designed for a specific distance in between the two coils, for example $d_{y}=40 \mathrm{~mm}$ as in Figure 12.

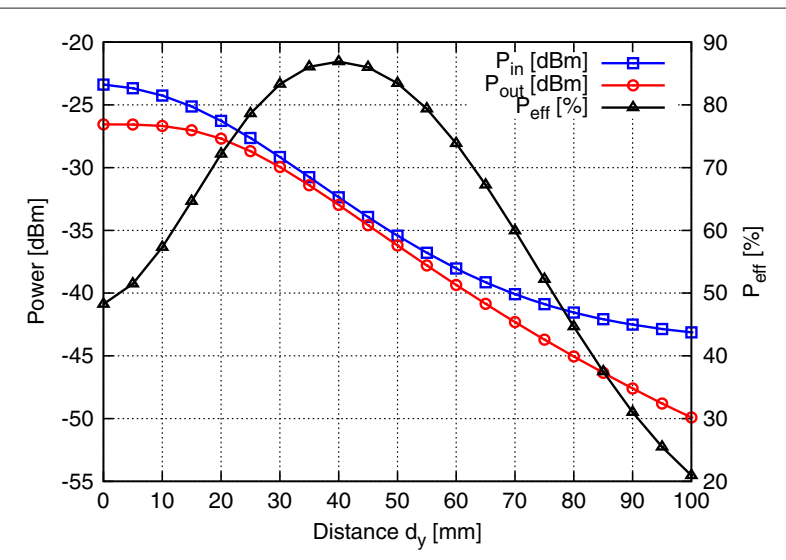

Figure 12 Simulated transmitted power vs coil distance $d_{y}$ (case of perfectly aligned coils, i.e. $\boldsymbol{d}_{\boldsymbol{x}}=\mathbf{0}$ and $\Theta=\mathbf{0}$ ). Generated voltage is $V_{\text {ins }} \leq 1.5 \mathrm{~V}$.

\section{Rectifier}

Most modern IC rectifier/charge-pump topologies are derived from the conventional multistage Dickson circuit [47], with modern variants based on self- $V_{\text {th }}$-cancellation (SVC) methodology published [48], where each twodiodes-two-capacitors stage acts as a voltage doubler, therefore contributing the $2\left(\hat{V}_{\text {in }}-V_{D}\right)$ voltage overdrive to the output, where $\hat{V}_{\text {in }}$ is the peak input voltage while $V_{D}$ is the diode turn-on voltage, and the diodes are implemented by MOS devices in CMOS technology. Hence, $V_{D}$ is equivalent to a MOS threshold voltage, $\left|V_{\text {th }}\right|$.

Our version of a three stage SVC type rectifier/chargepump, Figure 13, also uses the conventional NMOS as the base reference, and it was optimized for medical RF wireless band. Depending upon the load presented to the rectifier, the time required by the output node to reach the constant voltage level may vary between 100ns and tens of microseconds (for low input voltage levels) (Figure 14).

Therefore, an important overall design compromise is the power efficiency of the rectifier circuit by itself, which is (for the given distance between the external and implanted coil) characterized as the function of the input RF signal frequency and the voltage $V_{\text {ins }}$ generated across the implanted coil, Figure 15. Our design is, currently, optimized for frequency range between $400 \mathrm{MHz}$ and $1.2 \mathrm{GHz}$, and the input voltage levels in between 600 to $800 \mathrm{mV}_{\mathrm{pp}}$. Under these conditions the simulated power efficiency is more than $80 \%$. Lower input voltage levels result in apparent higher efficiency (i.e. close to 100\%), however the transistors are operating in sub-threshold region and, therefore, the total useful power drops by orders of magnitude, which creates the additional design constrain. For future implantable circuits that can operate in deeper sub $1 \mathrm{~mW}$ power region this mode of operation may be more suitable. 


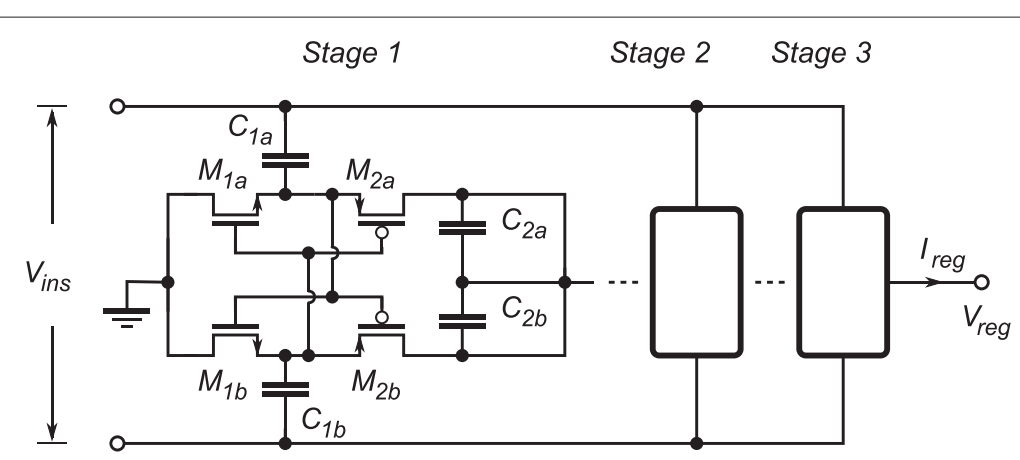

Figure 13 Simplified schematic diagram of the three stage CMOS rectifier/charge pump.

\section{Voltage regulator}

Utilizing energy collected at the receiver coil requires some sort of feedback control circuit that includes a rectifier, regulator and a bandgap voltage reference to deliver a stable, load-independent voltage to the circuit [49].

The widely fluctuating voltage generated by the chargepump is regulated by a series regulator, which by itself has to work with very low power and low-voltage [50], if it is to be useful for implantable medical telemetry systems. Schematic block diagram of our regulator architecture, Figure 15, shows that a compromise between the voltage drop across $M_{00}$ and overall PSRR is made based on the specific application conditions.

The regulation feedback loop is formed by the amplifier OP, the PMOS driver $M_{0}$ and the voltage divider $R_{1}$ and $R_{2}$ network, which sets the ratio between $V_{\text {PWR }}$ and $V_{\text {ref }}$ voltages as

$$
V_{\mathrm{PWR}}=\left(1+\frac{R_{1}}{R_{2}}\right) V_{\mathrm{rff}}
$$

The voltage reference $V_{\text {ref }}$ is then routed back to the input of the loop. The loop is designed to be stable with wide range of load impedances, with full load set up to

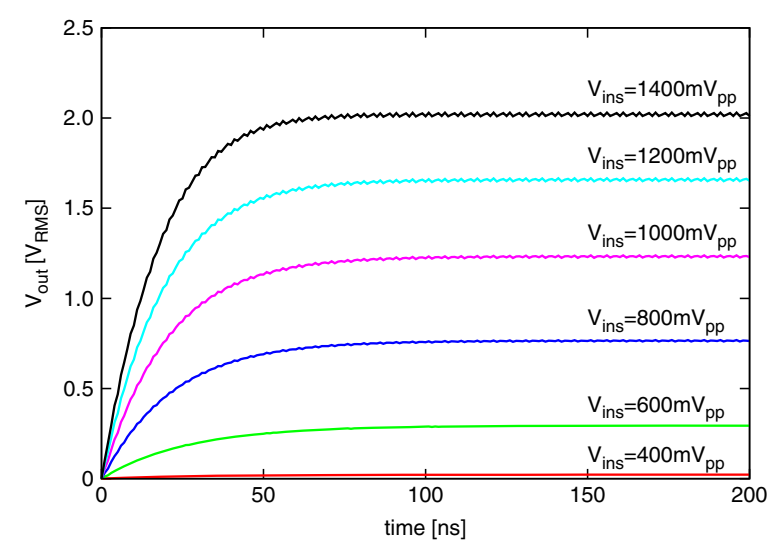

Figure 14 Simulated time-domain response of the rectifier/charge pump circuit without $M_{00}$ transistor.
$R_{L}=250 \Omega$ and $C_{L}=50 \mathrm{pF}$. The maximum load corresponds to the maximum current drawn from $V_{\mathrm{PWR}}$, which is designed to be $I_{\mathrm{PWR}}(\max )=4 \mathrm{~mA}$, which is far above the needs of our implantable telemetry electronics. By powering the reference circuit (BG) from $V_{\mathrm{PWR}}$, the overall PSRR of the $V_{\text {ref }}$ is further improved. In this design, the regulated supply voltage is set to $V_{\mathrm{PWR}}=0.985 \mathrm{~V}$ while the complete regulator consumes less than $11.6 \mu \mathrm{A}$ current (typically). The reference voltage also serves as a load to the regulator loop, which helps to keep the loop stable when its load is at the minimum.

\section{Power supply rejection ratio (PSRR)}

By using simulations we compared the regulator performance versus two different structures of operational amplifier. In terms of PSRR, the regulator based on foldedcascode amplifier with the $M_{00}$ relative to the 2-stage amplifier exhibits approximately $6 \mathrm{~dB}$ better PSRR in the LF range (i.e. $-45 \mathrm{~dB}$ vs. $-51 \mathrm{~dB}$ ), which increases to $15 \mathrm{~dB}$ in the mid-band, and becomes similar in the HF band. In both cases, the PSRR is dominated by $M_{00}$ which improves the PSRR. At the same time, the bandgap voltage reference by itself exhibits $-68 \mathrm{~dB}$ PSRR at LF and over $-80 \mathrm{~dB}$ at HF (Figure 16).

The complete regulator circuit is also simulated with range of loading impedances, and the simulation confirmed that in the worst case scenario, the fully-loaded regulated supply with folded-cascode amplifier, the reference voltage $V_{\text {ref }}$ is stable for voltage supply in the range of $1.3-1.9 \mathrm{~V}$ with a power supply sensitivity of $2.97 \mathrm{ppm} / \mathrm{V}$. For moderate to low impedance loads, the reference operates with supply voltages as low as $0.9 \mathrm{~V}$, while the regulated power supply voltage may be as low as $1 \mathrm{~V}$ (Figure 17).

\section{RF telemetry system}

In the previous sections we have seen that a batteryless low-power implant electronic system is critical for realizing the RF implantable wireless telemetry $[51,52]$. Once 


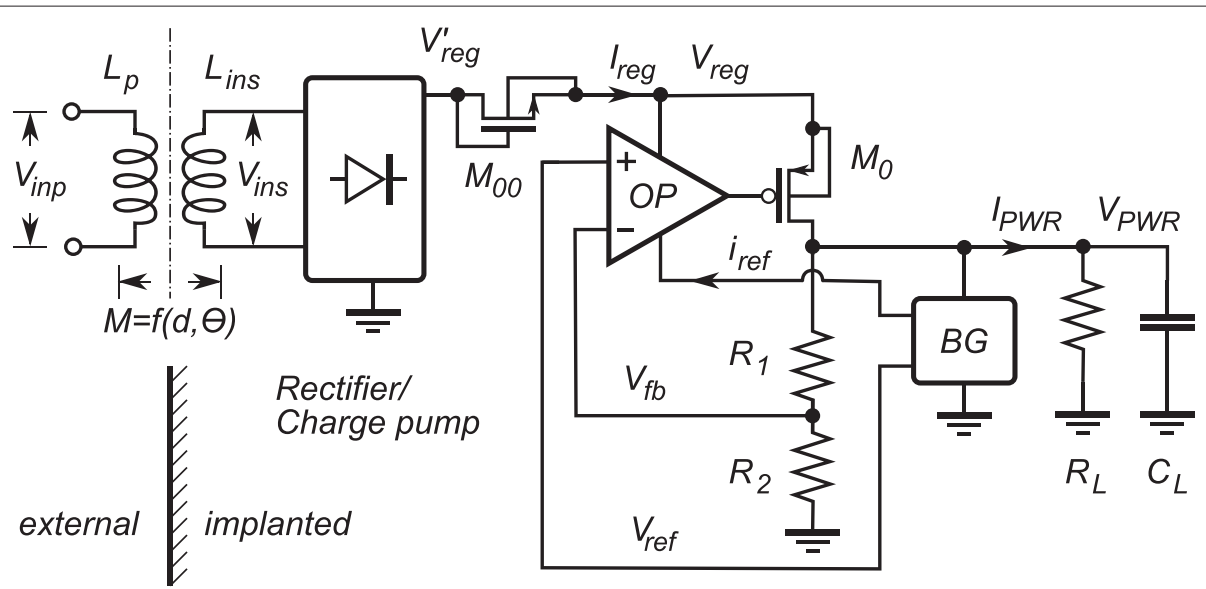

Figure 15 Block digram of energy harvesting front-end circuit showing the inductors, rectifier/charge pump and closed-loop regulation with amplifier and bandgap (BG) voltage/current reference, (the compensation $\boldsymbol{R}_{C} \boldsymbol{C}_{\boldsymbol{C}}$ network not shown). We characterized the circuit operation both with $M_{00}$ included, i.e. when $V_{\text {reg }}^{\prime} \neq V_{\text {reg, }}$ and without it, i.e. when $V_{\text {reg }}^{\prime}=V_{\text {reg. }}$.

the harvesting energy system designed, the remaining part of the implantable telemetry consists of the sensor interface, RF transmitter, and the controlling logic (Figure 9).

Our discrete version of a complete implantable RF telemetry system for cardiac monitoring using PV sensor, Figure 18 (shown with a LiPo micro-battery), is integrated into a cube shaped volume of about $13.5 \mathrm{~mm}$ a side, which amounts to $2.475 \mathrm{~cm}^{3}$ and it weights $2.67 \mathrm{~g}$ without the battery. The top two PCB modules in the stack are used for PV sensor interface circuit, which are followed down by RF transceiver, microprocessor, and power supply/regulator PCB modules.

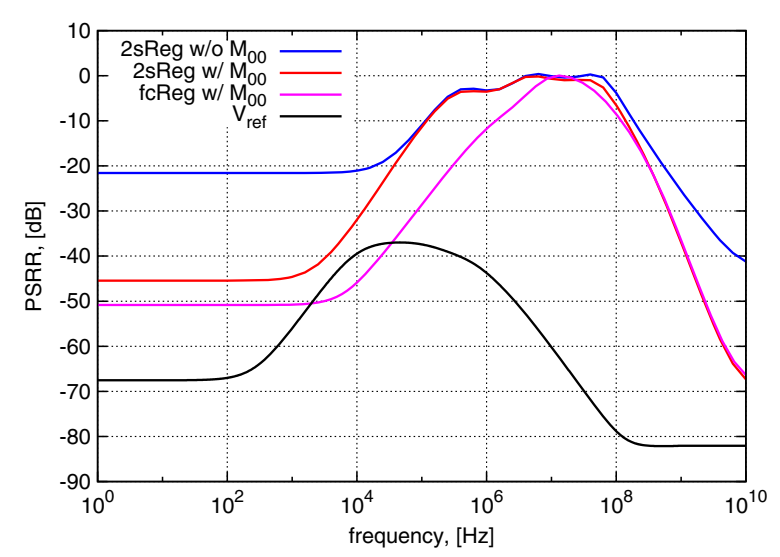

Figure 16 Simulated graphs for PSRR of $V_{\text {PWR }}$ vs. frequency of the closed loop regulator driving a load $\left(R_{L}=250 \Omega\right)$ : using a two-stage classical amplifier without $M_{00}$ transistor (2sReg w/o $\left.M_{00}\right)$; using a two-stage classical amplifier with $M_{00}$ transistor (2sReg w/ $M_{00}$ ); using folded-cascoded amplifier with $M_{00}$ transistor ( $\mathrm{fcReg} \mathrm{w} / M_{00}$ ); and PSRR of the voltage reference itself ( $\left.V_{\text {ref }}\right)$, (Typical process, $T=37^{\circ} \mathrm{C}, V_{\mathrm{PWR}}=1.0 \mathrm{~V}$ ).

\section{PV sensor interface}

A single-unit dual-sensor for conductance based PV measurements consists of two sensors in encapsulated a catheter. While the pressure sensor is based on a MEMS Wheatstone bridge structure $\left(R_{1}, R_{2}, P_{1}, P_{2}\right)$ and is stimulated by a $\mathrm{DC}$ current reference $\mathrm{DC}_{\text {ref }}$, the volume sensor (the four rings $(a, b, c, d)$ ) is stimulated by voltage reference $\mathrm{AC}_{\text {vref }}$ that is converted into current reference $\mathrm{AC}_{\text {iref }}$. Two operational amplifiers $\mathrm{OP}$ and the signal processing unit deliver the pressure $P_{\text {out }}$ and volume $V_{\text {out }}$ analogue levels (Figure 19). Complexity and power consumption of this interface is dominant relative to the overall size and the power consumption of the complete telemetry system. Further effort is needed to further reduce power consumption of both the PV sensor itself, as well as the required interfacing electronics [52].

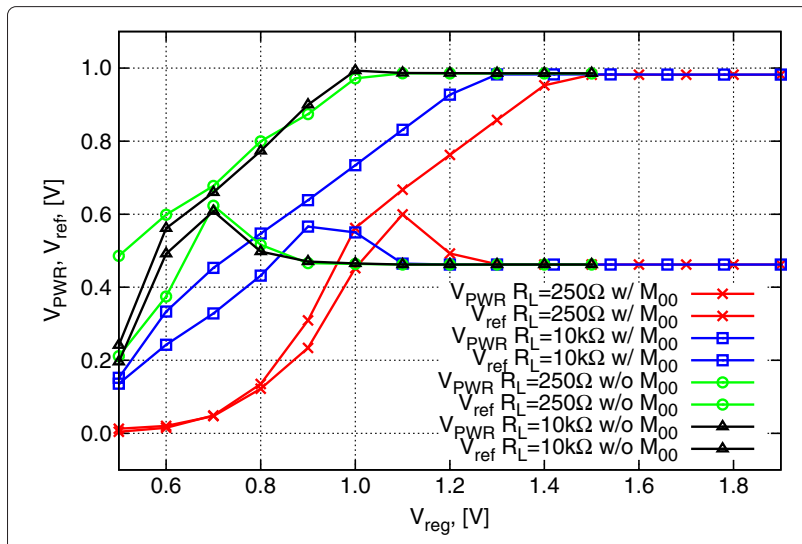

Figure 17 Simulated output of the reference and regulator (using folded-cascode amplifier) voltages versus variation of the supply voltage (full load). 

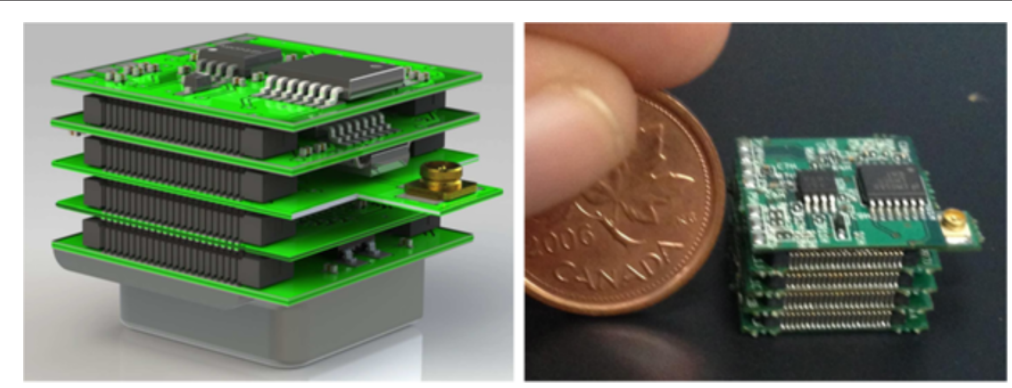

Figure $183 \mathrm{D}$ rendering of our complete RF telemetry system (left), and the manufactured unit compared to a Canadian penny (right).

The complete system occupies a volume of $2.475 \mathrm{~cm}^{3}$, and it weights $2.67 \mathrm{~g}$ without or $4.01 \mathrm{~g}$ with a micro LiPo battery.

\section{RF transmitter}

A conventional low-power oscillator-based transmitter, Figure 20, is a good choice for transmitting the digitized blood volume-pressure information to an external receiver by using the traditional frequency-shift keying (FSK) modulation. This kind of transmitter has reduced sensitivity to distance and orientation between the transmitter antenna and external receiving antenna, which is suitable for wireless animal monitoring. A carrier frequency choice of $433 \mathrm{MHz}$ from an Industrial, Scientific, and Medical (ISM) radio band provides good compromise due to the availability of commercial receivers in this band. Additionally, the $433 \mathrm{MHz}$ frequency is also good compromise in respect to the excessive transmission loss through live tissues. At the same time, it is high enough to allow that a small coil-based antenna can be employed [24,53], or even to work with a non-standard shaped antenna [25].

\section{Biocompatible package and antenna}

A living organism presents an extremely hostile environment for electronic circuits, which puts very harsh requirements on the overall system design, including constrains on specifications of the implantable package. For instance, while the specific shape and size of an eye predetermine possible options in terms of the system packaging and the antenna design $[54,55]$, the overall eye volume provides relatively comfortable volume for implanting the modern HF antennas [26]. In addition, the design methodologies of implantable flexible antennas suitable for biomedical research remain vigorously pursued topic [56].

Moreover, even a casual review of contemporary experimental works specifically in the area of implantable RF telemetry for cardiac monitoring may lead to the conclusion that the currently used design methodology does

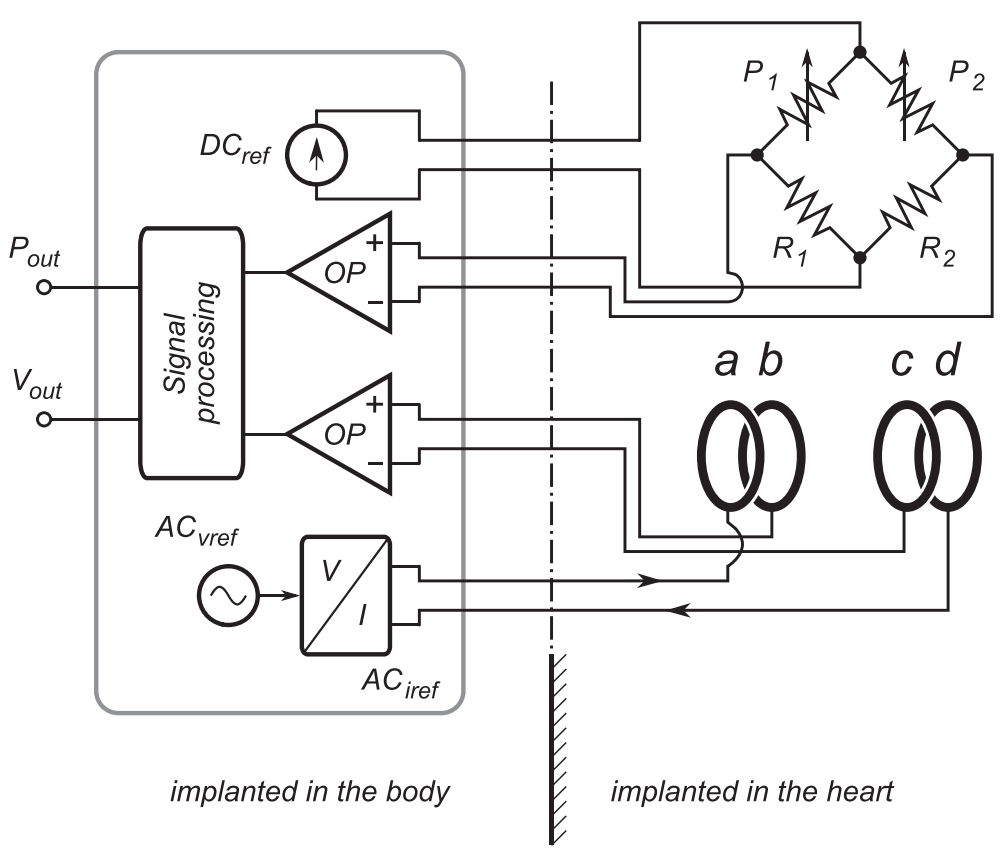

Figure 19 Simplified block diagram of PV catheter based sensor interface. 

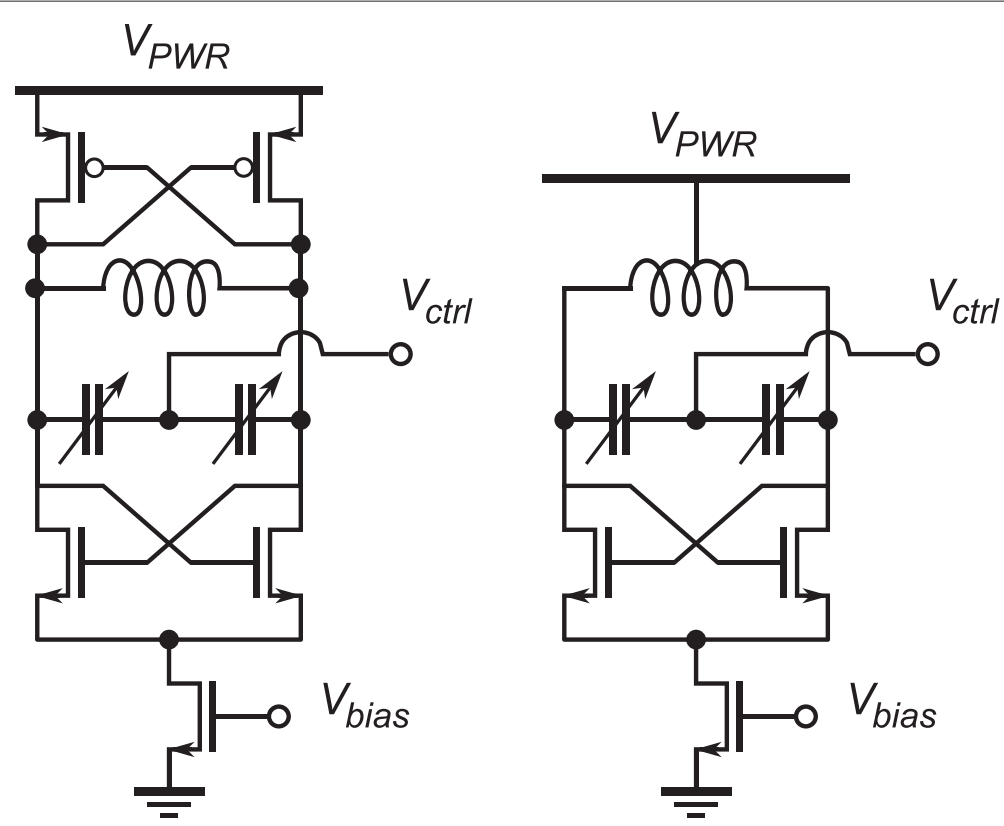

Figure 20 Simplified schematic diagram of a conventional VCO with NMOS current source (left), and its equivalent low-voltage version (right).

not result in the systems that occupy the minimum volume allowed by the current technology. Thus, the current package designs may not be fully optimized mostly due to the constrains and technology limitations related to the geometry of the package/antenna/system assembly (Figure 21).

For instance, a typical system level assembly includes an active integrated circuit connected to the external RF coil, and then the assembly is sealed with a biocompatible material [24]. Consequently, each section of the system

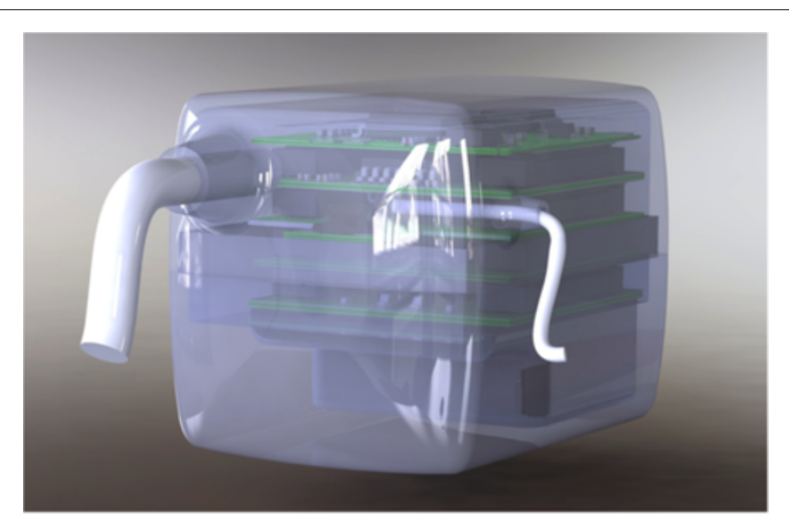

Figure 21 3D rendering of our current implantable package, which is designed to encompass the complete telemetry system, Figure 18. The PV catheter is connected to the telemetry using a 7-wire bundle (on the front side of the package), while the antenna is made of a single thin wire (on the right side of the package). appears to be designed separately using different design tools, which are then integrated at the system's top level.

On the other hand, when a larger volume is available inside the patient to place the complete telemetry/antenna assembly, then there is also a room for a more creative approach and more integrated overall package design. As an example, Chow et al. [25] presented their package/antenna analysis within the content of the medical stent application. In our design, we aim to derive the minimum volume system that includes the electronics, the package, and the antenna.

\section{Conclusion}

A number of research groups around the world have already focused their respective efforts on development of implantable telemetry technologies. Thus, when the core of an RF telemetry system for cardiac monitoring is reduced to $(2 \times 2 \times 2) \mathrm{mm}^{3}$ volume or less and, more importantly, when it is interfaced with various sensors it will drastically expand the list of potential industrial and scientific applications. Eventually, a wireless sensor network will be embedded, for instance, into crop fields, various constructions, and into a human body. That will enable real-time monitoring of growing crops, bridge integrity, or human health. This will then open up a wide range of other possible new applications for this potentially disruptive technology.

Competing interests

The authors declare that they have no competing interests. 


\section{Acknowledgements}

The author would like to express sincere gratitude to Scisense Inc, OCE, NSERC, $\mathrm{CFI}$, and CMC Microsystems for providing support for our research. Additionally, I acknowledge contribution of Mr. Sorin Popa who created some of the plots and verified data used in this article. Also, I acknowledge cited contributions from the referenced sources used in this review.

Received: 20 November 2012 Accepted: 7 January 2013

Published: 11 March 2013

\section{References}

1. Statistics Canada. Mortality, Summary List of Causes. Catalogue no. 84F0209X, Table 1-1: 14, 2008

2. DA Kass, T Yamazaki, D Burkhoff, WL Maughan, K Sagawa, Determination of left ventricular end-systolic pressure-volume relationships by the conductance (volume) catheter technique. Circulation. 73, 586-595 (1986)

3. CS Sander, JW Knutti, JD Meindl, A monolithic capacitive pressure sensor with pulse-period output. IEEE Trans. Electr. Dev. 27(5), 927-930 (1980)

4. J Baan, T Jong, P Kerkhof, R Moene, A van Dijk, E van der Velde, A Koops, Continuous stroke volume and cardiac output from intra-ventricular dimensions obtained with impedance catheter. Cardiovasc. Res. 15 , 328-334 (1981)

5. J Baan, ET van der Velde, HG de Bruin, GJ Smeenk, J Koops, AD van Dijk, D Temmerman, J Senden, B Buis, Continuous measurement of left ventricular volume in animals and humans by conductance catheter. Circulation. 70, 812-823 (1984)

6. Scisense Inc. http://www.scisense.com/. Accessed 2012/11/02

7. Millar Inc. http://www.millar.com/. Accessed 2012/11/02

8. MC Herrera, JM Olivera, MdIA Gómez López, in IEEE 32nd International Conference EMBC. Implantable hemodynamic monitors: can be conductance catheter system successfully implemented? (Buenos Aires, Argentina, 2010), pp. 3549-3552

9. VK Zworykin, JT Farrar, A 'radio pill'. Nature. 179, 898 (1957). [A note]

10. MRaDT Yuce, telemetry Easy-to-swallow wireless. IEEE Microwav. Mag. 9, 90-101 (2012)

11. JP Carson, AP Kuprat, $X$ Jiao, F del Pin, DR Einstein, An anisotropic fluid-solid model of the mouse heart. Comput. Cardiol. 36, 377-380 (2009)

12. G Mur, J Baan, Computation of the input impedances of a catheter for cardiac volumetry. IEEE Trans. Biomed. Eng. BME-31(6), 448-453 (1984)

13. CL Wei, JW Valvano, MD Feldman, JA Pearce, Nonlinear conductance-volume relationship for murine conductance catheter measurement system. IEEE Trans. Biomed. Eng. 52(10), 1654-1661 (2005)

14. A Kottam, J Dubois, A McElligott, HK Henderson, in IEEE 33rd International Conference EMBS1. Novel approach to admittance to volume conversion for ventricular volume measurement (Boston MA, USA, 2011), pp. 2514-2517

15. CL Wei, MH Shih, Calibration capacity of the conductance-to-volume conversion equations for the mouse conductance catheter measurement system. IEEE Trans. Biomed. Eng. 56(6), 1627-1634 (2009)

16. B Gopakumaran, JH Petre, B Sturm, RD White, PA Murray, Estimation of current leakage in left and right ventricular conductance volumetry using a dynamic finite element model. IEEE Trans. Biomed. Eng. 47(11), 1476-1486 (2000)

17. C Jacoby, A Molojavyi, U Flögel, MW Merx, Z Ding, I Schrader, Direct comparison of magnetic resonance imaging and conductance microcatheter in the evaluation of left ventricular function in mice. Basic Res. Cardiol. 101, 87-95 (2006)

18. CD Garson, Y Li, JA Hossack, Free-hand ultrasound scanning approaches for volume quantification of the mouse heart left ventricle. IEEE Trans. Ultrason. Ferroelectr. Freq. Control. 5, 966-977 (2007)

19. SA Detombe, FL Xiang, J Dunmore-Buyze, JA White, Q Feng, D Drangova, Rapid microcomputed tomography suggests cardiac enlargement occurs during conductance catheter measurements in mice. J. Appl. Physiol. 113, 142-148 (2012)

20. JA Paradiso, T Starner, Energy scavenging for mobile and wireless electronics. IEEE Pervasive Comput. 1, 18-27 (2005)
21. AK RamRakhyani, S Mirabbasi, M Chiao, Design and optimization of resonance-based efficient wireless power delivery systems for biomedical implants. IEEE Trans. Biomed. Circ. Syst. 5, 48-63 (2011)

22. KM Silay, C DM Dehollain, Inductive power link for a wireless cortical implant with two-body packaging. IEEE Sensors J. 11(11), 2825-2833 (2011)

23. S Kim, JS Ho, Y PAS, Wireless power transfer to miniature implants: transmitter optimization. IEEE Trans. Antennas Propag. 10, 4838-4845 (2012)

24. P Cong, N Chaimanonart, WH Ko, JD Young, A wireless and batteryless 10-bit implantable blood pressure sensing microsystem with adaptive RF powering for real-time laboratory mice monitoring. IEEE J. Solid-State Circ. 44(12), 3631-3644 (2009)

25. EY Chow, AL Chlebowski, S Chakraborty, WJ Chappell, PP Irazoqui, Fully wireless implantable cardiovascular pressure monitor integrated with a medical stent. IEEE Trans. Biomed. Eng. 57(6), 1487-1496 (2010)

26. YC Shih, T Shen, BP Otis, A $2.3 \mu \mathrm{W}$ wireless intraocular pressure/temperature monitor. IEEE J. Solid-State Circ. 46(11), 2592-2601 (2011)

27. R Njuguna, V Gruev, Low power programmable current mode computational imaging sensor. IEEE Sensors J. 12(4), 727-736 (2012)

28. M Schuettler, M Huegle, JS Ordonez, J Wilde, F Stieglitz, in IEEE 32nd International Conference EMBC. A device for vacuum drying, inert gas backfilling and solder sealing of hermetic implant packages (Buenos Aires, Argentina, 2010), pp. 1577-1580

29. TY Lin, D Ha, WN de Vries, B Kim, A Chlebowski, SWM John, PP Irazoqui, WJ Chappell, in IEEE MTT-S International Microwave Symposium Digest (MTT). Ultra-thin tag fabrication and sensing technique using third harmonic for implantable wireless sensors (Baltimore, MD USA, 2011), pp. 1-4

30. AL Dekker, GG Geskes, AA Cramers, WR Dassen, JG Maessen, KB Prenger FH van der Veen, Right ventricular support for off-pump coronary artery bypass grafting studied with bi-ventricular pressure-volume loops in sheep. Eur. J. Cardio-thoracic Surg. 19, 179-184 (2001)

31. C Gabriel, S Gabriel, RW Lau, E Corthout, The dielectric properties of biological tissues: literature survey. Phys. Med. Biol. 41, 2231-2269 (1996). [These are two papers combined]

32. CC Wu, TC Skalak, TR Schwenk, CM Mahler, A Anne, PW Finnerty, HL Haber, RMI Weikle, MD Feldman, Accuracy of the conductance catheter for measurement of ventricular volumes seen clinically: effects of electric field homogeneity and parallel conductance. IEEE Trans. Biomed. Eng. 44(4), 266-277 (1997)

33. JE Porterfield, ATG Kottam, K Raghavan, D Escobedo, JT Jenkins, ER Larson, RJ Treviño, JW Valvano, JA Pearce, MD Feldman, Dynamic correction for parallel conductance, $G_{P}$, and gain factor, $\alpha$, in invasive murine left ventricular volume measurements. J. Appl. Physiol. 107, 1693-1703 (2009)

34. S Popa, K Fricke, R Sobot, in IEEE International Conference for Upcoming Engineers, ICUE, vol. 2012. Calibration and finite element numerical analysis of an admittance based volume sensor for the murine heart (Toronto ON, Canada, 2012), pp. 12-13

35. A Kamitani, S Morishita, H Kotaki, S Arscott, Miniaturized microDMFC using silicon microsystems techniques: performances at low fuel flow rates. J. Micromech. Microeng. 18(12), 1-9 (2008). [125019]

36. BI Rapoport, JTSR Kedzierski, A glucose fuel cell for implantable brain-machine interfaces. PLoS ONE. 7(6) (2012). doi:10.1371/ journal.pone. 0038436

37. J Olivo, S Carrara, G De Micheli, Energy harvesting and remote powering for implantable biosensors. IEEE Sensors J. 11(7), 1573-1586 (2011)

38. F Mounaim, M Sawan, Toward a fully integrated neurostimulator with inductive power recovery front-end. IEEE Trans. Biomed. Circ. Syst. 6(4), 309-318 (2012)

39. N Tesla, Apparatus for transmitting electrical energy. Patent number:1,119,732, Filing date: 18 Jan, 1902,Issue date: 1 Dec, 1914

40. A Kurs, A Karalis, R Moffatt, JD Joannopoulos, P Fisher, M Soljačić, Wireless power transfer via strongly coupled magnetic resonances. Science. 317(5834), 83-86 (2007)

41. HA Haus, W Huang, Coupled-mode theory. IEEE Proc. 79(10), 1505-1518 (1991)

42. L Luo, K De Gannes, K Fricke, S Senjuti, R Sobot, in The 4th International EURASIP Workshop on RFID Technology, RFID 2012. Low-power CMOS 
voltage regulator architecture for implantable RF circuits (Torino, Italy, 2012)

43. D Russell, D McCormick, A Taberner, P Nielsen, P Hu, D Budgett, M Lim, S Malpas, in IEEE Biomedical Circuits and Systems Conference, BioCAS 2009. Wireless power delivery system for mouse telemeter (Beijing, China, 2009), pp. 273-276

44. S Senjuti, K Fricke, A Dounavis, R Sobot, in IEEE Canadian Conference on Electrical and Computer Engineering, CCECE2012. Misalignment analysis for resonance-based wireless power transfer to biomedical implants (Montreal QC, Canada, 2012), pp. 1-5

45. K Bong, E Levi, Z Zabar, L Birenbaum, Mutual inductance of noncoaxial circular coils with constant current density. IEEE Trans. Mag. 33(5), 4303-4309 (1997)

46. S Babic, C Akyel, Calculating mutual inductance between circular coils with inclined axes in air. IEEE Trans. Magnet. 44(7), 1743-1750 (2008)

47. J Dickson, On-chip high-voltage generation in MNOS integrated circuits using an improved voltage multiplier technique. IEEE J. Solid-State Circ. 11(3), 374-378 (1976)

48. K Kotani, A Sasaki, T Ito, High-efficiency differential-drive CMOS rectifier for UHF RFIDs. IEEE J. Solid-State Circ. 44(11), 3011-3018 (2009)

49. M Zargham, P Gulak, in IEEE International Symposium on Circuits and Systems (ISCAS). High-efficiency CMOS rectifier for fully integrated $\mathrm{mW}$ wireless power transfer (Zarg12, Seoul, Korea, 2012), pp. 2869-2872

50. D Yeager, F Zhang, A Zarrasvand, N George, T Daniel, B Otis, $9 \mu \mathrm{A}$ addressable Gen2 sensor tag for biosignal acquisition. IEEE J. Solid-State Circ. 45(10), 2198-2209 (2010)

51. P Cong, W Ko, D Young, Wireless batteryless implantable blood pressure monitoring microsystem for small laboratory animals. IEEE Sensors J. 10(2), 243-254 (2010)

52. K Fricke, Wireless telemetry system for implantable sensors. Master's thesis, Western University, Canada, 2012

53. NJ Cleven, JA Muntjes, H Fassbender, U Urban, M Gortz, H Vogt, M Grafe, T Gottsche, T Penzkofer, T Schmitz-Rode, W Mokwa, A novel fully implantable wireless sensor system for monitoring hypertension patients. IEEE Trans. Biomed. Eng. 59(11), 3124-3130 (2012)

54. EY Chow, AL Chlebowski, PP Irazoqui, A miniature-implantable RF-wireless active glaucoma intraocular pressure monitor. IEEE Trans. Biomed. Circ. Syst. 4(6), 340-349 (2010)

55. C Varel, YC Shih, B Otis, T Shen, K Bohringer, in IEEE 25th International Conference on Micro Electro Mechanical Systems (MEMS). Packaging for a wireless intraocular pressure sensor with a solder-filled microchannel antenna (Paris, France, 2012), pp. 981-984

56. M Scarpello, D Kurup, H Rogier, D Vande Ginste, F Axisa, J Vanfleteren, W Joseph, L Martens, G Vermeeren, Design of an implantable slot dipole conformal flexible antenna for biomedical applications. IEEE Trans. Antennas Propag. 59(10), 3556-3564 (2011)

\section{doi:10.1186/1687-3963-2013-1}

Cite this article as: Sobot: Implantable RF telemetry for cardiac monitoring in the murine heart: a tutorial review. EURASIP Journal on Embedded Systems 2013 2013:1

\section{Submit your manuscript to a SpringerOpen ${ }^{\circ}$ journal and benefit from:}

- Convenient online submission

- Rigorous peer review

- Immediate publication on acceptance

- Open access: articles freely available online

- High visibility within the field

- Retaining the copyright to your article

Submit your next manuscript at $\boldsymbol{\wedge}$ springeropen.com 